\title{
Effect of Teaching Program on Nurse`s Performance Regarding Guillian Barre Syndrome Patients at Neurological Care Unit.
}

\author{
Shimaa E. Abdelmonem, Ghydaa A. Shehata, Mervat A. Abdelaziz \& Asmaa A. Mahgoub. \\ Specialist nursing at neurological hospital, Assuit University, Egypt. \\ Professor of neurology medicine, faculty of medicine, Assuit University, Egypt. \\ Assistant professor of critical care and emergency nursing, faculty of nursing, Assuit University, Egypt. \\ Lecturer of critical care and emergency nursing, faculty of nursing, Assuit University, Egypt.
}

\begin{abstract}
Aim of the study: the study was aimed to evaluate the effect of teaching program on nurse`s performance regarding Guillian Barre Syndrome patients at neurological Care Unit at Assuit University Hospital. Research design: Quasi experimental research design was utilized in the study. Subject and method: the study was carried out on a convenience 30 nurses who participating in Guillian Barre patient care. One tool have been utilized to gather the information, tool I structure questionnaire divided into three parts: part 1 demographic characteristics of the nurses, part 2 pre/post knowledge assessment questionnaire, part 3 pre/post practice observational checklist. Tool had been utilized in 3 phases; preparatory, implementation and evaluation phase, with applying of teaching program for nurses about knowledge and practice about the care of Guillain-Barre syndrome patients. Results: The frequent of nurses had unsatisfactory whole expertise pre teaching program $(12.56 \pm 2.45)$ compared with post teaching program $(21.5 \pm 1.52)$ the suggest score had been improved significantly $(\mathrm{P}=0.000)$, additionally the majority of nurse's practice have been inadequate pre teaching program (127.93 \pm 44.58$)$ compared with post teaching program (248.5 \pm 9.11$)$. Conclusion: the find out about used to be illustrated that the teaching program leads to improvement in nurse`s knowledge about Guillain-Barre syndrome patients. Recommendation: Continuous nursing training and preparing programs on neurological intensive care unit should be well planned at Assiut university hospital.
\end{abstract}

\section{Keywords: Guillain-Barre Syndrome, Teaching Program, Nurse`s Performance.}

\section{Introduction}

Guillian Barre syndrome (GBS) is an auto immune sickness when the body`s immune system assaults part of the peripheral nervous system. The disease can have an impact on the nerves which manage muscle improvement as nicely as those that bring pain, temperature, and contact sensations. This can lead to muscle tissues weakness and loss of sensation in the legs and arms. (Blake, 2016)

The correct reasons for GBS are not identified, but around $75 \%$ of patients have records of previous contamination of the respiratory and gastrointestinal tract. An in any other case un-notable infection, such as an upper respiratory tract infection, frequently originates earlier than the beginning of GBS by means of 10 to 14 days.(Willison, 2016)

The myelin sheaths of the peripheral nerves are the pursuits of the auto immune response. The nerve's myelin sheaths are crucial for conveying nerve impulses. Sometimes instances the nerve axons are additionally attacked. At the factor when the myelin sheath is step by step removed, nerves can't carry statistics such as touch sensations to the brain, consequently the numbness. (Jacobs, 2016)

The first signs and symptoms of GBS normally commence with parenthesis, tingling and numbness of the lower extremities, muscle weak point of the legs progress swiftly for ascending loss of motion which include the trunk, upper extremities and facial muscle mass which lead to entire loss of motion, situation in chewing, swallowing and talking. The cranial nerves are included; loss of sensation and sphincter issues of bladder and rectum, absence of reflexes is moreover taken note. Failure of respiratory muscle may also be taking place when the respiratory muscle tissues characteristic is affected. (Hartung, 2012)

The diagnosis of GBS is built up on medical findings and nerve conduction studies in addition to patient history.The major aspects of GBS are hastily dynamic bilateral and distinctly symmetric weak point of the limbs with or without involvement of respiratory muscles or cranial nerve innervated muscles. Weakness would possibly in a similar fashion have an effect on all limb muscles, or overwhelmingly the distal or proximal muscle groups in the palms or legs. Patients have reduced or missing profound ligament reflexes, at least in the affected limbs. (WHO, 2016)

There is no recognized remedy for GBS. The point of the cure diagram is to cut back the seriousness of the ailment and to help in the patient's recovery. Treatment of GBS can be separated into processes for dealing with the severely paralyzed patient requiring intensive care and respiratory help and particular therapy aimed to ameliorating or reversing the nerve 
damage. Treatment may additionally comprise :( high dose intravenous immunoglobulin therapy (IVIG), plasma-pharesis, and corticosteroids). (Pritchard, 2016)

Common complications for patients with GBS comprise thrombophlebitis, stress ulcers, muscle wasting, sepsis, joint contractures, respiratory tract infections, respiratory failure, and loss of bladder and bowel control. (Winer, 2016)

The nursing care for the patient with GBS incorporates a variety of nursing diagnosis and interventions. The goal of nursing care is to support all normal body functions, prevent complications and decrease side effect of treatment. Although the condition is reversible, the patient with GBS requires extensive long term care because recovery can be a long process.(Benamer, 2014)

Critical care nurses should assess the patient frequently to monitor the patients for deterioration. Because of the progressive nature of the disease, assessment should focused on the neurological examination (cranial nerve involvement, reflexes, motor weakness, and sensory changes).cranial nerve deficits identify if the patient is at risk for aspiration. The patient's level of numbness, tingling, and pain should be assessed. (Bradly, 2016)

Nurses have a crucial role to play in helping patients live safety and in optimal health, through their holistic approach and professional expertise. Nurse address clients physical .psychological, emotional, spiritual and socioeconomic needs, they are also key educate in the effort to reduce the risk of complications.(Soliven, 2016)

\section{Aim of the study}

The study was aimed to evaluate effect of teaching program on nurse's performance regarding Guillian Barre Syndrome patients at neurological Care Unit.

\section{Research Hypotheses}

1) The post mean knowledge scores of nurses who are getting teaching program weregreater than pre mean knowledge scores.

2) The post mean practice scores of nurses who are getting teaching program were greater than prepractice scores.

\section{Patient \& Methods}

\section{Research design:}

A quasi experimental research design was utilized to conduct this study.

\section{Setting}

The study was carried out at neurological intensive care unit at Assuit University hospital.

\section{Sample}

- A convenient nurses (30 nurses) who participating in Guillian Barre patient care.

\section{Tools of the study}

One tool were utilized to accumulate the records in this find out about and created by using researcher based totally on analysis of texts.

Tool I: Structure questionnaire

This tool consisted of three parts:

Part 1:Demographic characteristics of the nurses:

This part include assessment of demographic characteristics of the nurses which includes age, sex, qualification, years of experience, training course, and training course about Guillian Barre syndrome.

\section{Part 2: Pre/post knowledge assessment questionnaire:}

This part advanced by the researcher after revising the texts to check nurse's knowledge about GBS incorporates (Definition, causes, signs and symptoms, complication such as (failure of respiratory muscles), and nursing care).Scoring system for nurse's knowledge:

All items had four alternative answers. A score value of (1) was awarded to each correct answer and zero (0) was allotted for wrong answer. The total scores of nurse`s knowledge was calculated and classified as follows:less than $60 \%$ was regarded as unsatisfactory level of knowledge, and equal or above $60 \%$ was regarded as satisfactory level of knowledge.

\section{Part 3: Pre/post nurse`s practice observational} checklist:

This tool advanced by the researcher after revising the texts used to assess nurse's practice about GB patient care such as nursing care for the patient associated with mechanical ventilation, intubated patient, infusion pump, blood transfusion, enteral feeding, and care for patient with tracheostomy.

Scoring system for nurse`s skills. The total score for all steps was 148 and every step was evaluated as follows: correctly done was scored (2),incorrectly done was scored (1), and not done was scored (0).The total score of nurse's skills was calculated and classified as follows:less than $60 \%$ was regarded as un adequate level of practice, andequal or above $60 \%$ was regarded as adequate level of practice.

\section{Methods}

- An official authorization will be gained from Dean of faculty of nursing and head of department of neurological intensive care unit.

- Ethical consideration, the nature and the destinations of the study was described to every personnel.

- Consent was once full from taking part personnel after of clarifying the nature and the goals of the study.

- Confidentiality and anonymity of the subjects are guaranteed through coding the data. 
- The tool two utilized in the study about was once improved by way of the researcher built on reviewing the relevant literature.

- Content validity of tools: The equipment have been examined for content validity through judges of 5 professionals in the discipline of imperative care nursing and neurological Medicine at Assuit University and the imperative changes had been done.

- Reliability was assessed via Cronbach's Alpha for all equipment and its result was once 0.89 which used to be recognized. -The pilot study: Pilot was carried out on three nurses to take a look at applicability of the tools then vital changes had been done in accordance to the results of the pilot learn about and expertise views.

Research implementation

This study was carried out at three phases:

Phase I: Preparatory phase

A survey of current and past, nearby and global related literature in a variety of factor the usage of books, articles and periodicals, the journal was once done. This proposed find out about putting was surveyed for a range of nurses collaborating in GBS patients care at neurological intensive care unit, this ended by a pilot study.

-Assess nurse`s demographic characteristics which include age, sex, qualification, years of experiences, training course, and training course about Guillian Barre Syndrome using part 1.

-Assess nurse's knowledge about Guillian Barre affected person care with deciding their educational necessities using part 2.

-Assess nurse`s practice about Guillian Barre affected person care using part 3.

Phase III: Implementation phase

-All nurses were questioned during break time (one hour) in different shift or before beginning of shift.

\section{1) Assessment of nurse`s demographic}

\section{characteristics:}

-The researcher assess demographic characteristics of nurses which include age, sex, qualification, years of experiences, training course, and training course about Guillian Barre Syndrome.

\section{2) Assessment of knowledge was done twice as}

\section{follows:}

- Once at the starting of study was considered as pretest assessment and as baseline information for ultimate contrast with future posttest.

-The second utilization of questionnaire was carried out post application of the teaching program to detect its effect on nurse`s knowledge.

\section{2) Assessment of nurse`s practice}

-The researcher located the nurse`s practice utilizing observational checklist device twice pre and post teaching program application.

Implementation of program

For theoretical content:

Teaching program has been implemented for nurses in term of session with total six sessions. Number of nurses in each session was 6 nurses. The duration of each session was a one hour, including 10 minutes for discussion and feedback. Each session usually end with summary of what has been taught during this session.

\section{$=$ Preliminary session:}

In this session the researcher met the participants and explained the objectives, content and method of evaluation of program. For duration one hour.

=Session I included: Anatomy and physiology of nerve cells and definition of GBS. For duration one hour.

=Session II included: causes, pathophysiology, and signs and symptoms of GBS. For duration one hour.

=Session III included: Treatment of GBS, types of treatment. For duration one hour.

=Session IV included: complications of treatment and nursing care during receiving treatment. For duration one hour.

=Session IIV included: complication of the disease and nursing care for patient with Guillian Barre syndrome. For duration one hour.

For practical content:

The researcher was conducting demonstration using teaching materials (photos). This was done on five sessions. Number of nurses in each session was 6 nurses. The duration of each session was a one hour, including 10 minutes fordiscussion and feedback.

=Session I included: Oropharngeal airway suction and care, care for intubated patient, and care for extubated patient. For duration one hour.

=Session II included:Arterial blood gases and its interpretation, and care for patient with pulse oximetery. For duration one hour.

=Session III included:Care for patient with tracheostomy, care for patient on oxygen therapy, and care for patient with Ryle feeding. For duration one hour.

=Session IV included: Care for patient on infusion pump and receiving blood transfusion. For duration one hour.

=Session IIV included: Care for patient on mechanical ventilation. For duration one hour.

-Theoretical and practical content were repeated according to the ability of understanding.

-The researcher provided each patient with the designed illustrated booklet. 
Phase (IV): Evaluation phase

The contrast of program was once authorized immediately after the application of the program the usage of the posttest learn about equipment to take a look at the effectively of the program on nurse's knowledge and practice.

\section{Result}

Table (1): Distribution of nurse`s demographic characteristics of the studied nurses $(n=30)$.

\begin{tabular}{|c|c|c|}
\hline Variables & $\mathbf{N}$ & $\%$ \\
\hline \multicolumn{3}{|l|}{ Age: } \\
\hline $20---25$ & 14 & 46.7 \\
\hline $26----30$ & 10 & 33.3 \\
\hline$>30$ & 6 & 20.0 \\
\hline Mean \pm SD & \multicolumn{2}{|c|}{$27.47 \pm 5.32$} \\
\hline \multicolumn{3}{|l|}{ Sex: } \\
\hline Female & 30 & 100.0 \\
\hline Male & 0 & 0.0 \\
\hline \multicolumn{3}{|l|}{ Qualification : } \\
\hline Baclelor of nursing & 4 & 13.3 \\
\hline Technician institute of nursing & 12 & 40.0 \\
\hline Diploma & 14 & 46.7 \\
\hline \multicolumn{3}{|l|}{ Years of experience: } \\
\hline$<10$ & 18 & 60.0 \\
\hline$\geq 10$ & 12 & 40.0 \\
\hline Mean \pm SD & \multicolumn{2}{|c|}{$7.86 \pm 6.31$} \\
\hline \multicolumn{3}{|l|}{ Training course: } \\
\hline Yes & 10 & 33.3 \\
\hline No & 20 & 66.7 \\
\hline \multicolumn{3}{|l|}{ Training course about GBS: } \\
\hline Yes & 0 & 0.0 \\
\hline No & 30 & 100.0 \\
\hline
\end{tabular}

Data described as ( $n \& \%)$ chi-squar and (mean $\pm S D)$ independent sample t-test

Table (2): Distribution of knowledge scores achieved by nurses pre and post applying of teaching program $(n=30)$ about information of Guillian- Barre Syndrome.

\begin{tabular}{|c|c|c|c|c|c|}
\hline \multirow[t]{2}{*}{ Nurse`s knowledge level } & \multicolumn{2}{|c|}{$\begin{array}{c}\text { Pre test } \\
(n=30)\end{array}$} & \multicolumn{2}{|c|}{$\begin{array}{c}\text { Post test } \\
(n=30)\end{array}$} & \multirow[t]{2}{*}{ p-value } \\
\hline & $\mathbf{N}$ & $\%$ & $\mathbf{N}$ & $\%$ & \\
\hline Un satisfactory $(<60 \%)$ & 25 & 83.3 & 0 & 0.0 & \\
\hline Satisfactory $(\geq 60 \%)$ & 5 & 16.7 & 30 & 100.0 & $0.000 *$ \\
\hline Mean \pm SD & \multicolumn{2}{|c|}{$1.166 \pm 0.379$} & \multicolumn{2}{|c|}{$2.000 \pm 0.000$} & 0.000* \\
\hline
\end{tabular}

* statistically significant difference $(p<0.05) \quad$ Data described as (mean $\pm S D)$ independent sample $t$-test

Table (3): Practice scores attained by nurses pre and post applying of the teaching program $(n=30)$.

\begin{tabular}{|c|c|c|c|c|c|}
\hline \multirow[t]{2}{*}{ Nurse`s practice level } & \multicolumn{2}{|c|}{$\begin{array}{c}\text { Pre test } \\
(n=30)\end{array}$} & \multicolumn{2}{|c|}{$\begin{array}{c}\text { Post test } \\
(n=30)\end{array}$} & \multirow[t]{2}{*}{ p-value } \\
\hline & $\mathbf{N}$ & $\%$ & $\mathbf{N}$ & $\%$ & \\
\hline Un adequate $(<60 \%)$ & 27 & 90.0 & 0 & 0.0 & \multirow[b]{2}{*}{$0.000 *$} \\
\hline Adequate $(\geq 60 \%)$ & 3 & 10.0 & 30 & 100.0 & \\
\hline Mean \pm SD & \multicolumn{2}{|c|}{$1.1 \pm 0.305$} & \multicolumn{2}{|c|}{$2.000 \pm 0.000$} & $0.000 *$ \\
\hline
\end{tabular}

* statistically significant difference $(p<0.05)$

Data described as (mean $\pm S D)$ independent sample t-test and ( $n \& \%)$ chi-squar. 
Table (4): Total practice scores of care of patient with mechanical ventilation attained by nurses pre and post applying of the teaching program $(n=30)$.

\begin{tabular}{|l|c|c|c|c|c|}
\hline \multirow{2}{*}{$\begin{array}{c}\text { Nurse`s practice level } \\
\text { (care of mechanical ventilation) }\end{array}$} & \multicolumn{2}{|c|}{$\begin{array}{c}\text { Pre test } \\
(\mathbf{n}=\mathbf{3 0})\end{array}$} & \multicolumn{2}{c|}{$\begin{array}{c}\text { Post test } \\
(\mathbf{n}=\mathbf{3 0})\end{array}$} & \multirow{2}{*}{ p-value } \\
\cline { 2 - 5 } & $\mathbf{N}$ & $\mathbf{\%}$ & $\mathbf{N}$ & $\mathbf{\%}$ & \\
\hline Un adequate $(<\mathbf{6 0} \%)$ & 20 & 66.7 & 0 & 0.0 & \multirow{2}{*}{$\mathbf{0 . 0 0 0 *}$} \\
\hline Adequate $(\geq \mathbf{6 0 \% )}$ & 10 & 33.3 & 30 & 100.0 & \multirow{2}{*}{$\mathbf{0 . 0 0 0 *}$} \\
\hline Mean \pm SD & \multicolumn{2}{|c|}{$\mathbf{1 . 3 3} \pm \mathbf{0 . 4 7 9}$} & \multicolumn{2}{|c|}{$\mathbf{2 . 0 0 0} \pm \mathbf{0 . 0 0 0}$} & \\
\hline
\end{tabular}

*statistically significant difference $(p<0.05)$

Data described as (mean $\pm S D$ ) independent sample t-test and ( $n \& \%)$ chi-squar

Table (5): Correlation between demographic characteristics of the nurses with nurse`s performancepre and post applying of teaching program $(n=30)$.

\begin{tabular}{|l|c|c|c|c|c|c|c|c|}
\hline \multirow{2}{*}{\multicolumn{1}{|c|}{ Items }} & \multicolumn{2}{|c|}{ Age groups } & \multicolumn{2}{c|}{ Qualification } & \multicolumn{2}{c|}{$\begin{array}{c}\text { Years of } \\
\text { experience }\end{array}$} & \multicolumn{2}{c|}{$\begin{array}{c}\text { Training course } \\
\text { about Guillian } \\
\text { Barre syndrome }\end{array}$} \\
\cline { 2 - 9 } & $\mathbf{r}$ & $\mathbf{P}$ & $\mathbf{r}$ & $\mathbf{P}$ & $\mathbf{R}$ & $\mathbf{P}$ & $\mathbf{r}$ & $\mathbf{P}$ \\
\hline $\begin{array}{l}\text { Pre -test total score } \\
\text { knowledge }\end{array}$ & -0.312 & $0.093^{\mathrm{ns}}$ & -0.206 & $0.135^{\mathrm{ns}}$ & -0.104 & $0.550^{\mathrm{ns}}$ & -0.951 & $\mathbf{0 . 3 0 5}^{\mathrm{ns}}$ \\
\hline $\begin{array}{l}\text { Post- test total score } \\
\text { knowledge }\end{array}$ & -0.403 & $0.027^{*}$ & -0.309 & $0.193^{\mathrm{ns}}$ & -0.195 & $0.262^{\mathrm{ns}}$ & -0.180 & $\mathbf{0 . 2 6 0}^{\mathrm{ns}}$ \\
\hline $\begin{array}{l}\text { Pre -test total score } \\
\text { practice }\end{array}$ & -0.206 & $0.275^{\mathrm{ns}}$ & -0.085 & $0.520^{\mathrm{ns}}$ & -0.019 & $0.913^{\mathrm{ns}}$ & -0.106 & $\mathbf{0 . 8 7 2}^{\mathrm{ns}}$ \\
\hline $\begin{array}{l}\text { Post- test total score } \\
\text { practice }\end{array}$ & -0.074 & $0.699^{\mathrm{ns}}$ & -0.108 & $0.735^{\mathrm{ns}}$ & -0.107 & $0.541^{\mathrm{ns}}$ & -0.209 & $\mathbf{0 . 3 0 2}^{\mathrm{ns}}$ \\
\hline
\end{tabular}

$N S=$ no statistical significant difference

*statistically significant difference $(p<0.05)$

Table (1): This table confirmed that; the frequent of nurses $(46.7 \%)$ of them had been in age group equal or much less than 25 years, $(100.0 \%)$ are female. Regarding their academic level, $(46.7 \%)$ of the nurse held three years nursing diploma, $(40.0 \%)$ of the nurse held technical institute of nursing, and (13.3\%) of the nurse held Bachelor of nursing. Also, (60.0\%) of nurse had work experience much less than 10 years and $(40.0 \%)$ of them had more than or equal 10 years. In with respect to their preceding training about GBS, this table shows that $(100.0 \%)$ of them have been not accepting any previous GBS preparing. Table (2): This table demonstrated the mean scores for total knowledge of nurses about Guillian Barre syndrome. It showed that there is highly significance differences between pre $(12.56 \pm 2.45)$ and post $(21.5 \pm 1.52)$ application of the teaching program $(\mathrm{P}=0.000$ * respectively) as regard of knowledge about Guillian Barre syndrome.

Table (3): This table demonstrate the mean scores for total practice pre and post application of program. It showed that there is highly significance differences between pre $(127.93 \pm 44.58)$ and post $(248.5 \pm 9.11)$ application of the teaching program $(\mathrm{P}=0.000 *$ respectively) as regard of practice of care of about the treatment of Guillian Barre syndrome patients.
Table (4): This table established that there is an exceedingly sizable statistically variations $(\mathrm{P}=0.000)$ in nurse`s overall practice in comparison between pre and post application of the teaching program involving care of mechanical ventilation.

Table (5): This table shows that; there was no positive correlation has been founded between demographic characteristics and pre -test total score questionnaire, post- test total score questionnaire, pre -test total score observational checklist and post- test total score observational checklist ; and there no statistically significant difference except age groups and post-test total score questionnaire $(\mathrm{p}=0.027$ respectively).

\section{Discussion}

The existing study was conducted on a sample 30 nurses who working in neurological intensive care. The common of the nurses their age was from 20-25, female. The frequent of them have experiences less than ten years. The frequent of nurses have diploma was less than half. The end result of the study indicated that most of nurses had not trained and had unsatisfactory information about nursing care of GBS patients. 
The latest study published that, the degree of knowledge about GBS of the frequent of studied nurses frequently was poor, this can also be celebrated with the way that basic of them preserve nursing diploma and most of books are written in English and their schooling in Arabic, this motive a hassle for them to learn. Another motive for shortage of information is that all of them have been now not getting any previous training program about GBS.The research point of view, this lack of knowledge might be additionally due to lack of preemployment orientation programs, in-service GBS training program or courses.

After application of teaching program it was celebrated that the common of nurses show significant upgrading in the nurse`s knowledge about the treatment of GBS and care of the patient during receiving treatment. In this regard this finding concur with (Huan, 2014) who confirmed that the effectiveness of the teaching program in improving nurse`s knowledge about treatment and care for GBS patients.

The effect of the current study showed poor level of practice rankings in all gadgets pre application of teaching program about care of GBS patients. Possible motive published that nurses in the institute do now not supply energetic fingers on overall practice for the direct care for GBS patients. The nurses typically manipulate sufferers according to doctor instruction.

The result of the current study showed that the mean knowledge and practice enhanced post application of the teaching program than pre application the teaching program. It showed that the common of nurses had satisfactory mean knowledge and practice scores in post implementing the teaching program. This came back to these nurses included in the study were exposed to training program to care for such a group of patient, in agreement with (Fokke, 2014).

The result of the current study showed that age, years of experience, qualification and training course about Guillian Barre syndrome of nurses has no effect on nurse's knowledge and practice. There is no relation between demographic characteristics and nurse's knowledge and practice, this may due to shortage of information and increase of workload which may impedes their ability to read and update their knowledge.

At long last, it can be perceived that, the teaching program for nurses giving care for GBS patients has achieved its objectives by enhancing nurse's knowledge and practice regarding GBS patient care. This further was fortified by (Glover, 2010) who expressed that professional nurses have a large role to play in the minimization and prevention of GBS complications and should be clinically well versed in all aspects of the condition, current strategies to address risk minimization and prevention management and advocates for patient safety.

\section{Conclusions}

In view of the consequence of the present study, it can be concluded that:

-Nurse`s knowledge and performance about GBS in neurological intensive care unit at Assiut university hospital are inadequate. Nurses are really skilled to enhance their knowledge and performance after exposure to teaching program.

-Applying the teaching program on nurse's knowledge such as (definition, causes, signs and symptoms, complications, and treatment of GBS) and nurse's performance such as (endotracheal tube care and oropharngeal care) about GBS patients shows a significant improvement in nurse's knowledge and performance. Improving nurse's knowledge and performance can affect the incidence of GBS complications.

\section{Recommendations}

In view of after effects of the present study the following can be recommended:

1- Continuous nursing trainingand preparing programs on neurological intensive care unit should be well planned at Assiut university hospital.

2- Nurses should increasethe regular reading of upto-date references (periodical, textbooks, etc)to their routine responsibilities. They ought to undependably be to attend scientific meetings and conferences to keep step with the rapidly growing wealth of knowledge and performance necessary for proper nursing service.

3- Nurses in neurological intensive care unit are essential to successfully complete a test of basic knowledge and practice and before assuming independent responsibility for patient care.

\section{References}

1. Benamer H., \& Bredan A., (2014): GuillainBarre syndrome in Arab countries: a systematic review. J NeurolSci; 343:221-23.

2. Bowyer H., \& Glover M., (2010): Guillian Barre syndrome: management and treatment options for patients with moderate to severe progression. J NeurosciNurs; 42(5):288-293.

3. Bradly W., Daroff R., \& Fenichel. G., (2016): Neurology in Clinical Practice, Principles of diagnosis and management, 1117-1128.

4. Cao-Lormeau V., Blake A., \& Mons S., (2016): Guillain-Barré Syndrome outbreak associated with Zika virus infection in French Polynesia: a case-control study. Lancet; 387:1531-9. 
5. Cashman C., \& Hoke A., (2015): Mechanisms of distal axonal degeneration in peripheral neuropathies. NeurosciLett; 596:33-50.

6. Fokke C., Van Den Berg B., \& Drenthen J., (2014): Diagnosis of Guillain-Barre syndrome and validation ofBrighton criteria. Brain 2014; 137:33-43.

7. Goodfellow J., \& Willison H., (2016): GuillainBarré syndrome: a century of progress. Nat Rev Neurol; 12:723-31.

8. Hughes R., \& Cornblath D., (2016): GuillainBarré syndrome in the 100 years since its description by Guillain, Barré and Strohl. Brain; 139:3041-47.

9. Kokubun N., Shahrizaila N., Hirata K., \& Yuki N., (2013): Reversible conduction failure is distinct from neurophysiological patterns of recovery in mild demyelinating Guillain-Barre syndrome. J NeurolSci;326:111-14.

10. Lim J., Devaux J., \& Yuki N., (2014): Peripheral nerve proteins as potential autoantigens in acute and chronic inflammatory demyelinating polyneuropathies. Autoimmun Rev 2014; 13:1070-78.

11. Musso D., Cao-Lormeau V., \& Gubler D., (2015): Guillain-Barre syndrome common concerns. Following the path of dengue and chikungunya? Lancet 2015; 386:243-44.

12. Pritchard J., Hughes R., Hadden R., Brassington R., (2016): Pharmacological treatment other than corticosteroids, intravenous immunoglobulin and plasma exchange for Guillain-Barré syndrome. Cochrane Database system Rev; 11:CD008630.

13. Roodbol J., De Wit M., Aarsen F., (2014): Long-term outcome of Guillain-Barre syndrome in children. J PeripherNervSyst; 19:121-26.

14. Soliven B., (2016): Animal models of autoimmune neuropathy. ILAR J 2014; 54:28290.

15. Urden, L., Stacy, K., Lough, M., (2016): Priorities in Critical Care Nursing, 2016 Elsevier Inc, 793-797. at http://www.Researcher .net /publication /258348570.

16. Wakerley B., Yuki N., (2015): Mimics and chameleons in Guillain-Barre and Miller Fisher syndromes. PractNeurol; 15: 90-99.

17. Willison H., Jacobs B., van Doorn P., (2016): Guillain-Barré Syndrome. Lancet; 388:717-27.

18. Winer J., (2016): Guillian-Barre syndrome, clinical variants and the pathogenesis. J NeuroImmun; 31:70-72.

19. World Health Organization. (2016): diagnosis and management of Guillain-Barré syndrome; 22(6):864-873. At
20. Yuki N., \& Hartung H., (2012):Guillain-Barré syndrome. N Engl J Med; 366:2294-304. 